\title{
New Business Histories! Plurality in business history research methods
}

Stephanie Decker ${ }^{\mathrm{a}}$

Aston Business School, Aston University, Birmingham, UK

Matthias Kipping $^{\mathrm{b}}$

Schulich School of Business, York University, Toronto, Canada

R. Daniel Wadhwani ${ }^{\mathrm{c}}$

University of the Pacific, Stockton, California and Copenhagen Business School, Denmark

We agree with de Jong et al.’s argument that business historians should make their methods more explicit and welcome a more general debate about the most appropriate methods for business historical research. But rather than advocating one 'new business history', we argue that contemporary debates about methodology in business history need greater appreciation for the diversity of approaches that have developed in the last decade. And while the hypothesis-testing framework prevalent in the mainstream social sciences favoured by de Jong et al. should have its place among these methodologies, we identify a number of additional streams of research that can legitimately claim to have contributed novel methodological insights by broadening the range of interpretative and qualitative approaches to business history. Thus, we reject privileging a single method, whatever it may be, and argue instead in favour of recognizing the plurality of methods being developed and used by business historians - both within their own field and as a basis for interactions with others.

Keywords: research methods; interpretative and qualitative approaches; interactions with other disciplines

\footnotetext{
${ }^{\mathrm{a}}$ Email: s.decker@aston.ac.uk

b Email: mkipping@schulich.yorku.ca

cEmail: dwadhwani@pacific.edu
} 
We welcome the contributions of de Jong and Higgins, and de Jong, Higgins, and van Driel as a well-timed opportunity to engender a broader debate on the role of methods in business history research. ${ }^{1}$ De Jong, Higgins and van Driel rightly criticize business historians for the failure to be more explicit about the methodologies underpinning our research - a critique we have made in our own reflections on the topic. ${ }^{2}$ We think they are correct in their charge that the lack of careful discussion and explication of methods hampers the effectiveness of business historians in our interactions with other disciplines that are concerned with studying entrepreneurs, firms, business groups, industries, business systems, etc. Absent deeper consideration of how business history works as a field of research to make knowledge claims about our subjects of study, it is difficult for scholars (including ourselves) to grasp and evaluate how business history contributes to our understanding of business and management. We also believe that an engagement with methods is absolutely consistent with intellectual traditions within academic history, dating back to the origins of the discipline itself.

Thus, our comments and critiques here should in no way be understood as a defence of what de Jong et al. might consider to be the 'old' business history - a contrast implied in their argument, albeit never fully defined. Nor should our position be seen as a defence of business historians’ tendency to avoid quantitative evidence. Quantitative evidence, like qualitative evidence, can be analysed in different methodological ways. Such an old-new dichotomy conjures up the acrimonious and ultimately less than productive distinction that the 'new' economic historians of the 1960s and 1970s drew between themselves and what was clearly meant to imply the retrograde 'old' economic history. ${ }^{3}$ We believe that business history does not easily fit any categorization of the 'old' versus the 'new'. But more importantly, the main thrust of our comment is not so much a critique of the 'new' but of the singular. We argue that it is neither possible nor desirable to choose a single methodological 
framework for business history, and that it is more appropriate to speak of and foster the development of a variety of reflective methodologies in business historical research, hence the title: new business histories. Our argument is based on three lines of reasoning: first, that methods need to be understood in relation to the nature of the knowledge one is trying to produce and that, because historians produce different kinds of knowledge we logically need a variety of methodological frameworks; second, that when one surveys business history today we see evidence of multiple new directions in methods and research practices that suggests the need to think in the plural about the new business histories; and finally that fostering a plurality of methods is actually beneficial because it allows the production of different kinds of scholarly understanding of the phenomena of interest to business historians. The rest of this comment discusses each of these lines of reasoning in order.

\section{The Context for Methods}

The Oxford dictionary defines method as 'a particular procedure for accomplishing or approaching something, especially a systematic or established one. ${ }^{4}$ The definition reminds us of something that is often lost in procedural descriptions of methodology: that a method exists in the specific context of the purposes or ends for which it is designed, the 'accomplishing or approaching something' in the definition above. Change the end or purpose and one should rationally expect the method to change as well. The choice of methods is related to the epistemic goals one is trying to accomplish, and the goals of business historical research is already more diverse than could be achieved by any single methodological approach.

While this may seem relatively obvious when pointed out, there is a widespread tendency - even among business historians - to associate methods with the achievement of only one particular kind of epistemic goal: the identification and testing of specific 
hypotheses. We think the main limitation of de Jong's et al. framework is that it tends to focus on methods with this one goal in mind; hence its emphasis on hypothesis testing as the methodological way forward for business history. Yet, even if we think of business history as a science, the testing of specific claims are not the only scientific ends we seek. Historical research, for instance, is often aimed at uncovering sequences and processes, or at synthesizing complex developments related to the phenomenon being studied, rather than verifying specific claims. ${ }^{5}$ Such research aims are common not just in history, but also in many other social sciences. In such research, the intent is not to describe and analyse an event as a 'case' for the purposes of developing a testable claim, but rather to fully account for the particular, the specific instance or phenomenon under investigation through rich and detailed reconstruction. While de Jong and Higgins are right that the hypothesis testing approach is common across the social sciences, so are process and idiographic studies, particularly in fields such as anthropology, sociology and psychology, and also in a significant part of management research. ${ }^{6}$ Often, the events and developments we study in business history are understood as important in themselves, rather than as an instance of a testable rule or claim. The common emphasis in historical research on context and on the particular suggest the need for historians to consider methods appropriate to such goals - and that are hence equally valid and in no case inferior to those associated with testing specific hypotheses. ${ }^{7}$

The challenge of methods in history gets even more complex because of the inherently interpretive rather than descriptive or analytical character of much historical inquiry. ${ }^{8}$ Rowlinson, Hassard and Decker, for example, point to three major differences between those researching organizations from theories and methodologies based in history or the social sciences: the nature of evidence, the conceptualization of temporality, and the mode of explanation. ${ }^{9}$ In terms of evidence, historians typically do -or at least should- not treat information from the past as objectively accessible data that can be agglomerated into 
larger analytical models, but as sources that need to be critically understood and interpreted within the context of their creation and storage. ${ }^{10}$ In terms of temporality, historians usually interpret their subjects by creating periodizations and by moving back and forth in chronological time instead of assuming the even flow of time associated with analytical, longitudinal research. ${ }^{11}$ Finally, the predominant form of representation of historical research is narrative, which accounts for actors and action in relationship to a contextual whole and can incorporate multiple kinds of methodological approaches. In other words, the significance of an event or fact is derived from its position or role in the overall historical account rather than as a discrete, testable occurrence. ${ }^{12}$ In each of these instances, historical research tends to involve interpretive rather than analytical claims. Thus, while the hypothesis-testing approach that de Jong et al. espouse is an important and welcome methodological framework for some types of epistemic goals, it cannot serve as a means for the full range of scholarly inquiry in (business) history. Moreover, one only need look at the new directions that business history has taken recently to see the need for multiple approaches to methods, and the need to speak in the plural about the new business histories something we discuss in some more detail in the subsequent section.

\section{The Plurality of Business History}

There are, in fact, several dynamic streams of business historical research that have developed coherent intellectual dialogs in recent years. Here, we briefly focus on three of them: (i) studies inspired by the mainstream social sciences, which include De Jong's et al. new business history; (ii) the history of capitalism, which has some roots in labour and cultural history but is becoming more encompassing; and (iii) the growing number of historical studies within management and organizational research. Even within each of these streams, multiple methodological approaches to historical research are flourishing. 
De Jong's et al. program for a 'new' business history is oriented towards a dialogue with the mainstream social sciences, even though their approach remains committed to merging these methods with historical concerns of contextualization and contingency. Their proposals seem to be motivated in large part by the apparent success of those fields in the rigorous development and testing of hypotheses. But even within the mainstream social sciences there is variety in methods and there are many who would not espouse hypothesis testing as the only way forward. Take evolutionary economics, which has been used, for instance, by Lamoureux, Raff and Temin to provide an alternative account to Chandler for the rise of big business in the United States. ${ }^{13}$ One of its proponents, while having been trained as a neoclassical economist succinctly states 'that it is rare that issues of interest to business historians admit of statistically testable questions and rarer still that data on which such tests might be conducted are available to researchers' ${ }^{14}$ Likewise, there are the so-called social studies of economics and finance, which have gained currency following the recent financial crisis. Drawing on sociology, anthropology and ethnographic studies of science they argue that markets are shaped by -and not only explained by- economic theories and technological devices, pointing to the eminently social and historical dimension of financial models. ${ }^{15}$ This research often eschews hypothesis testing for interpretive methods.

A second example of alternatives to the hypothesis-testing methodology advanced by de Jong et al. can also be found in the scholarship of business historians engaged in dialogue with mainstream historians. The history discipline, in particular in the United States, had taken a cultural turn in the 1970s through the 1990s, which opened a gap with business history, at the time still dominated by the Chandlerian paradigm. ${ }^{16}$ While earlier calls for more interaction remained largely unheeded, there has recently been more openness from both sides, with some business historians espousing the postmodern, narrativist tenants of cultural studies, which have a significantly different, but no less valid, ontological, 
epistemological and methodological orientation than the proposed 'new business history'. ${ }^{17}$ Indeed, for many business historians, a deeper engagement with mainstream history seems to go hand in hand with a rejection of a narrowly defined application of scientific methods to historical subjects. For instance, in their recent programmatic book Scranton and Fridenson advocate 'a dialogue with fellow historians [...] in tandem with stepping away from our decades-long reliance on economics, economic history, and management science'. And they warn in particular against a 'rigorous, if narrow and formalistic application of an "empirical analytical approach” to securing knowledge'. ${ }^{18}$

A particularly vibrant stream of recent scholarship in this regard concerns the socalled 'history of capitalism', which emerged out of an impulse within US history departments to expand the boundaries of cultural history to address a range of issues shaping modern societies and economies: the power of firms and business people to not only influence markets but also politics and society; the impact of business on not only growth and wealth but also on its distribution; and the extensive interactions between markets and culture. ${ }^{19}$ One of its primary methodological contributions, in this regard, is in embracing a broader interpretive canvas than that of traditional business history, which tends to focus on business people, firms, and industries. For instance, histories of capitalism often encompass power relations (broadly conceived to include race, gender, class, ideology, institutions, and policies) in the development of business, markets, and economic systems. As such, it often offers new interpretations of business historical subjects by broadening the study of business to incorporate capitalist social and cultural relationships.

Finally, and most importantly for our own research practice, there have been many calls and a growing interest in taking history more seriously within organization and management studies. Most of this interest has grown out of a frustration with the naturalscience paradigm that increasingly came to dominate management research since the $1960 \mathrm{~s} .^{20}$ 
Thus, Zald for instance, criticized the almost exclusive use of the 'mantle of science and quantitative evidence' in organizational studies and argued instead for 'combining social science and the humanities' and, in particular for a 'systematic engagement with philosophy, historical methods, and literary and narrative theory' ${ }^{21}$ For some, this has meant a return to the management discipline's own Weberian roots ${ }^{22}$ - a tradition that had also influenced the earlier 'organizational synthesis' in business history, ${ }^{23}$ which addressed issues such as technology, political economy and professionalization that remain highly relevant for business historical and management research. For others the desired 'historic turn' in management studies represents an alternative, simplistically put post-modernist epistemological stance on organizations - a direction which some business historians have also espoused. ${ }^{24}$ Yet other historically inclined management scholars have drawn on Foucauldian concepts, including the notions of 'genealogy', to produce historical studies of organizations and their practices. ${ }^{25}$

In a recent survey Kipping and Üsdiken show that historical approaches are more prevalent in organization and management theory (OMT) than is widely believed and are continuing to gain traction. ${ }^{26}$ Many of these studies remain within the science paradigm, using historical sources as data to develop, modify and test theories - and hence would lend support the position taken by de Jong et al. However, others are integrating 'history' - albeit often as a rather stylized past - into their theoretical models as a driver or moderator for subsequent developments. But what Kipping and Üsdiken highlight as the most promising development for the future of history in OMT is the emergence of what they call 'historical cognizance', i.e. studies that went beyond history as data or driver and actually integrated historical contexts and their idiosyncrasies into theorizing efforts. Quite tellingly, some of these studies challenged Chandlerian accounts of the rise and evolution of big business - 
sometimes based on archive-based historical research - with the work by Freeland on organizational change at General Motors among the relevant examples. ${ }^{27}$

Likewise, Rowlinson, Hassard and Decker provide a glimpse into the variety of methodological approaches being applied in historical studies of business and other organizations. ${ }^{28}$ In particular, they identify four main strategies, labelled 'serial history', ‘corporate history’, 'analytically-structured history’ and 'ethnographic history’. Only the first of these relies on quantification through coding and/or analytical statistics. 'Corporate history’ by contrast relies largely on narrative, generally following a chronological structure. It may also use concepts such as the various business functions to organize the narrative, but will always subsume them within the analysis of the firm as a whole. A good example is the book on Unilever by Jones. ${ }^{29}$ Conversely, in ‘analytically-structured history’ organizations and their history are subsumed and narrated within broader analytical concepts. This is perhaps most evident in the work by Chandler on the visible hand or on strategy and structure. ${ }^{30}$ Other examples, with a focus on single organizations, are the above-mentioned work by Freeland, which centres on notions of power and control, and the recent study by Gelderblom, de Jong and Jonker on the origins of the Dutch East India Company. ${ }^{31}$ Last but not least, 'ethnographic history’ employs an interpretative-analytical approach that is focused on understanding the way in which people in the past conceptualized their environment, as exemplified by the work of McKinlay on careers or the recent article by Decker on corporate architecture and organizational memory. ${ }^{32}$

In sum, while often dealing with similar questions and issues, the social studies of economics and finance, the 'history of capitalism' and the various research streams in 'management and organizational history' are based on a range of different epistemological and methodological stances. Espousing a more narrowly focused hypothesis-testing approach as the methodological path forward-even if it is somewhat contextualized- would certainly 
stifle the dynamism that is apparent in this variety and make it difficult to reap the resulting benefits from such pluralism, which we will outline in the next section.

\section{The Benefits of Methodological Variety}

Acknowledging and embracing heterogeneity in historical methods is important not only because it represents the state of the field, but also because it has real research benefits for business history. A variety of methods are needed because business history researchers should be asking different kinds of questions and seeking different kinds of knowledge about the past. It also allows business historians to contribute to debates outside their own field and, potentially, to collaborate with scholars from other disciplines.

Looking at organization and management studies, which is closest to our own research interests, one finds a growing list of research topics to which historical approaches are contributing and where they even shape debates. Many of these contributions are being published in some of the leading management journals, both in Europe and in the United States, suggesting that they are becoming more mainstream. Even more importantly, the vast majority of these contributions do not rely exclusively and not even predominantly on hypothesis testing as their methodology contrary to a recent claim made by Eloranta, Valtonen and Ojala - ultimately rendering the insistence on hypothesis testing as the only way forward questionable.

For example, qualitative, interpretive, and process-based historical methods have become important in numerous research streams, including: (i) studies of entrepreneurship and organizational change; ${ }^{33}$ (ii) studies of institutions, institutionalization, and categorization; $^{34}$ (iii) the (critical) history of the management discipline itself, where recent research has questioned the ‘demonization’ of Taylorism and the ‘deification’ of Elton Mayo and the human relations school, and in general has provided much more historically 
contextualized accounts; ${ }^{35}$ and (iv) studies that investigate how firms use their history and heritage strategically, often based on in-depth case studies and, theoretically, combining views on legitimacy from institutional theory and insights from social memory studies. ${ }^{36}$ Other areas seem increasingly open for if not keen on a historical approach, with work on organizational processes offering particularly promising perspectives, in particular since it has been dominated by qualitative, albeit predominantly ethnographic methods. ${ }^{37}$ Interest in historical perspectives and approaches is also developing in studies on organizational capabilities, a concept that already attracted Chandler's attention, ${ }^{38}$ and where historical cases of organizational failure have offered relevant insights. ${ }^{39}$ Most of these research streams are thriving, and in some cases have found new vigour, by embracing multiple methodological approaches to research.

The benefits of this heterogeneity are very apparent in the recent book edited by Bucheli and Wadhwani, which features work by leading evolutionary sociologists ${ }^{40}$ and institutional theorists ${ }^{41}$ alongside historians ${ }^{42}$ and proponents of historical approaches in organization studies. ${ }^{43}$ Going forward, the book aims to provide avenues and a methodological basis for a differentiated multidisciplinary engagement between historians and social scientists. The above-mentioned reviews of research strategies for organizational history and history in organization and management theory, for instance, are already the product of a collaboration between business historians and management scholars. And a standing working group on 'Historical Perspectives in Organization Studies' at the colloquium of the European Group for Organizational Studies (EGOS) has provided an important annual forum for such interdisciplinary encounters. It is important to note that hardly any of the papers discussed there, be they from management scholars or business historians or jointly produced, have relied on hypothesis testing. 
Interestingly, management scholars do not seem to be attracted to historical approaches and a dialogue or collaboration with business historians based primarily on hypothesis testing. Quite the contrary: history appears of interest to management scholars because it provides alternative approaches to the dominant science paradigm and its hypothesis-testing methodology.

\section{Conclusion}

The new business histories of recent years point to the vibrant new directions in which business history is going and the varied purposes and conversations that are shaping each. Methods, properly understood in context, should further these goals and conversations, not constrain them. It is for this reason, also, that we prefer the plural, because it points to the multiple productive directions in which the field is going and the possibilities for conversation between them.

De Jong, Higgins, and van Driel provide a thoughtful introduction to one among a variety of new methodological approaches to business history. Ultimately, the designation 'new business histories' suggests a more productive and fruitful dialogue about the multiple ways to understand and study the past. The theory development-hypothesis testing framework is doubtlessly relevant to a sub-division of historical research that opts for what Rowlinson et al call a 'serial history' approach, but it co-exists within a whole spectrum of historical approaches to business. As we have shown, a substantial amount of work has already been published that offers new and innovative methodological avenues which would be distorted by the insistence on a hypothesis-testing approach. Indeed we have argued that de Jong's et al. 'new business history' is only partially reflective of history’s methodological traditions and its contemporary research strategies. The singular 'new' approach thus cannot 
account for the wide range and growing number of academic communities that business historians are currently engaging with in productive conversations.

\section{Acknowledgements}

Authors contributed equally. Names appear in alphabetical order. We thank Julia Ott, Louis Hyman, and Alfred Reckendrees, the editors of this special issue and an anonymous referee for their helpful comments and suggestions. The usual disclaimer applies.

\section{References}

Anteby, M. and V. Molnár. Collective memory meets organizational identity: Remembering to forget in a firm’s rhetorical history. Academy of Management Journal 55 (2012): $515-540$

Beckert, S. The Monied Metropolis: New York City and the Consolidation of the American Bourgeoisie. New York: Cambridge University Press, 2003.

Berg, B. L. and H. Lune. Qualitative Research Methods for the Social Sciences. Boston, MA: Pearson, 2012.

Boldizzoni, Francesco. The Poverty of Clio: Resurrecting Economic History, Princeton: Princeton University Press, 2011.

Bruce, Kyle and C. Nyland. "Elton Mayo and the Deification of Human Relations." Organization Studies 32, No. 3 (2011): 383-405.

Buchanan , D. A. and A. Bryman , A. (eds.). The SAGE Handbook of Organizational Research Methods. London: Sage, 2009.

Bucheli, Marcelo and R. Daniel Wadhwani. Organizations in Time: History, Theory, Methods. Oxford: Oxford University Press, 2014. 
Burgelman, Richard A. "Bridging history and reductionism: A key role for longitudinal qualitative research." Journal of International Business Studies 42 (2011): 591-601.

Callon, Michel. "Introduction: the embeddedness of economic markets in economics". The Sociological Review 46, Issue S1 (May 1998): 1-57.

Callon, Michel, Yuval Millo and Fabian Muniesa (Eds.). Market Devices. Oxford, WileyBlackwell, 2007.

Carter, Chris. "The Age of Strategy: Strategy, Organizations and Society, Business History 55, No. 7 (2013): 1047-1057.

Chandler, Alfred D. Jr. Strategy and structure. Chapters in the history of the industrial enterprise. Cambridge, Mass.: MIT Press, 1962.

Chandler, Alfred D. Jr. The Visible Hand: The Managerial Revolution in American Business. Cambridge, Mass.: The Belknap Press Harvard University Press, 1977.

Chandler, Alfred D. Jr. "Organizational Capabilities and the Economic History of the Industrial Enterprise." Journal of Economic Perspectives 6, No.3 (Summer 1992): 79100.

Clark, Peter and Michael Rowlinson. "The treatment of history in organisation studies: towards an 'historic turn'." Business History 46 (2004): 331-352.

Danneels, E. "Trying to Become a Different Type of Company: Dynamic Capabilities at Smith Corona." Strategic Management Journal 32, No. 1 (2011): 1-31.

de Jong, Abe, David Higgins and Hugo van Driel. "New Business History? An Invitation to Discuss". Business History, forthcoming

Decker, Stephanie. "The silence of the archives: business history, post-colonialism and archival ethnography." Management \& Organizational History 8 (2013): 155-173.

Decker, Stephanie. "Solid Intentions: An Archival Ethnography of Corporate Architecture and Organizational Remembering." Organization (2014) 
Eloranta Jari, H. Valtonen H and Jari Ojala. "Methods, Topics, and Trends in Recent Business History Scholarship." Association of Business Historians, ABH Newsletter 2010.

Engwall, Lars, Matthias Kipping and Behlül Üsdiken. "Public science systems, higher education and the trajectory of academic disciplines: Business studies in the United States and Europe.” In Richard Whitley, Jochen Gläser and Lars Engwall (eds.), Reconfiguring Knowledge Production. Oxford, Oxford University Press, 2010, pp. 325-353.

Fear, Jeffrey. "Mining the Past: Historicizing Organizational Learning and Change." In M. Bucheli and R. D. Wadhwani (eds), Organizations in Time: History, Theory, Methods. Oxford: Oxford University Press, 2014, pp. 169-191.

Foster William M., Roy Suddaby, A. Minkus et al. "History as social memory assets: The example of Tim Hortons." Management \& Organizational History 6 (2011): 101-120.

Freeland, Robert F. The Struggle for Control of the Modern Corporation: Organizational Change at General Motors, 1924-1970. Cambridge: Cambridge University Press, 2006.

Galambos, Louis. "The Emerging Organizational Synthesis in Modern American History." Business History Review 44, No. 3 (Autumn 1970): 279-290.

Galambos, Louis. “Technology, Political Economy, and Professionalization: Central Themes of the Organizational Synthesis.” Business History Review 57, No. 4 (Winter 1983): 471-493.

Galambos, Lou. "Is This a Decisive Moment for Business, Economic History, and the History of Capitalism?" Essays in Economic \& Business History 32 (2014), in press (http://www.ebhsoc.org/journal/index.php/journal/article/view/271/251) 
Gelderblom, Oscar, Abe de Jong and Joost Jonker. "The Formative Years of the Modern Corporation: The Dutch East India Company VOC, 1602-1623" (No. ERS-2012-007F\&A). Erasmus Research Institute of Management (ERIM), June 2012. Retrieved from http://hdl.handle.net/1765/32952

Hansen, Per H. "Organizational Culture and Organizational Change : The Transformation of Savings Banks in Denmark 1965-1990." Enterprise and Society 8, No. 4 (2007): 1-34. Hansen, Per H. "Business History: A Cultural and Narrative Approach." Business History Review 86, No. 4 (Winter 2012): 693-717.

Hansen Per H. and R. Daniel Wadhwani. "Can Business History and Anthropology Learn from Each Other?" Journal of Business Anthropology 3, No. 1 (2014): 51-59.

Hargadon, A. B., \& Douglas, Y. (2001). When innovations meet institutions: Edison and the design of the electric light. Administrative science quarterly, 46(3), 476-501.

Hassard, John S. "Rethinking the Hawthorne Studies: The Western Electric research in its social, political and historical context." Human Relations 65, No. 11 (2012): 14311461.

Hyman, Louis. Debtor nation: The history of America in red ink. Princeton University Press, 2011.

Jones, C., M. Maoret, F. G. Massa and S. Svejenova. "Rebels with a cause: Formation, contestation, and expansion of the de novo category "modern architecture,” 18701975." Organization Science 23 (2012): 1523-1545.

Jones, Geoffrey. Renewing Unilever. Transformation and Tradition. Oxford: Oxford University Press, 2005. 
Khaire, M. and R. D. Wadhwani. "Changing landscapes: The construction of meaning and value in a new market category—Modern Indian Art." Academy of Management Journal 53 (2010): 1281-1304.

Kieser, Alfred. "Why Organization Theory Needs Historical Analyses-And How This Should Be Performed." Organization Science 5 (1994): 608-620.

Kipping, Matthias and Behlül Üsdiken. "History in Organization and Management Theory: More Than Meets the Eye." The Academy of Management Annals 8, No. 1 (2014): 535-588, in press (http://dx.doi.org/10.1080/19416520.2014.911579)

Kipping, Matthias, R. Daniel Wadhwani and Marcelo Bucheli M. "Analyzing and Interpreting Historical Sources: A Basic Methodology." In M. Bucheli and R. D. Wadhwani (eds.), Organizations in Time. Oxford: Oxford University Press 2014, 305330.

Kipping, Matthias and Juha Antti-Lamberg. "Historical methods." In Ann Langley and Haridimos Tsoukas (eds.), The SAGE Handbook of Process Organization Studies, London, Sage, 2015.

Lamoreaux Naomi R., D. M. G. Raff and Peter Temin. "Beyond markets and hierarchies: toward a new synthesis of American business history." American Historical Review, April 2003.

Langley, Ann. "Strategies for theorizing from process data." Academy of Management Review 24, No. 4 (1999): 691-710.

Lipartito, Kenneth. "Culture and the practice of Business History." Business and Economic History, 24 (1995): 1-42.

Lipartito, Kenneth. "Historical Sources and Data. In M. Bucheli and R. D. Wadhwani (eds.), Organizations in Time: History, Theory, Methods. Oxford: Oxford University Press, 2014, pp. 284-304. 
Lippmann, S. and Howard E. Aldrich. "History and Evolutionary Theory." In M. Bucheli and R. D. Wadhwani (eds.), Organizations in Time: History, Theory, Methods. Oxford: Oxford University Press, 2014, pp. 124-146.

Maclean Mairi, Charles Harvey and Robert Chia. "Sensemaking, storytelling and the legitimization of elite business careers." Human Relations 65 (2012): 17-40.

McKinlay, Alan. "'Dead Selves': The Birth of the Modern Career." Organization 9 (2002): 95-614.

McKinlay, Alan. "Following Foucault into the archives: clerks, careers and cartoons." Management \& Organizational History 8 (2013): 137-154.

Mihm, S. A nation of counterfeiters: Capitalists, con men, and the making of the United States. Harvard University Press, 2009.

Mordhorst, Mats. "From counterfactual history to counter-narrative history." Management \& Organizational History 3 (2008): 5-26.

O'Connor, Ellen S. "The Politics of Management Thought: A Case Study of the Harvard Business School and The Human Relations School." Academy of Management Review 24 (1999): 117-131.

Ott, J. C. When Wall Street Met Main Street. Harvard University Press, 2011.

Popp, Andrew and R. Holt R. "Entrepreneurship and the organization of being: the case of the Shaws." Entrepreneurship and Regional Development 25 (2013): 52-68.

Popp, Andrew and R. Holt. "The presence of entrepreneurial opportunity." Business History 55 (2013): 9-28.

Raff, D. M. G. "How to Do Things with Time." Enterprise and Society 14 (2013): 435-466.

Ricoeur, P. Time and narrative. Volume I. Trans. K. McLaughlin and D. Pellauer. Chicago: University of Chicago Press, 1984 
Rowlinson, Michael and John Hassard. "History and the Cultural Turn in Organization

Studies." In M. Bucheli and R. D. Wadhwani (eds), Organizations in Time: History, Theory, Methods. Oxford: Oxford University Press, 2014, pp. 147-168.

Rowlinson, Michael, John Hassard and Stephanie Decker. "Research Strategies for

Organizational History: A Dialogue between Historical Theory and Organization Theory." Academy of Management Review 39 (2014): PAGES

Schwarzkopf, Stefan. "What is an archive - and where is it? Why business historians need a constructive theory of the archive." Business Archives: Sources and History 105 (2012): 1-9.

Sewell, William H. Logics of History: Social Theory and Social Transformation. Chicago: University of Chicago Press, 2005.

Stinchcombe, A. L. The Logic of Social Research. Chicago: the University of Chicago Press, 2005.

Suddaby, Roy, William M. Foster and Albert J. Mills. "Historical Institutionalism." In: mM. Bucheli and R. D. Wadhwani (eds), Organizations in Time: History, Theory, Methods. Oxford: Oxford University Press, 2014, pp. 100-123.

Suddaby, Roy, William M. Foster and C. Q. Trank. "Rhetorical History as a Source of Competitive Advantage." Advances in Strategic Management 27 (2010): 147-173. Tripsas, Mary and G. Gavetti. "Capabilities, Cognition, and Inertia: Evidence from Digital Imaging." Strategic Management Journal 21, Nos. 10-11 (2000): 1147-1161. Üsdiken, Behlül and Matthias Kipping. "History and Organization Studies: A Long-term View”, in Marcelo Bucheli and Dan Wadhwani (eds.), Organizations in Time: History, Theory, Methods, Oxford, Oxford University Press, 2014. 
Wadhwani, R. Daniel and Marcelo Bucheli. "The Future of the Past in Management and Organization Studies." In M. Bucheli and R. D. Wadhwani (eds), Organizations in Time: History, Theory, Methods. Oxford: Oxford University Press, 2014, pp. 3-32. Winter, Sidney G. "An Evolutionary Program for Business History?" Enterprise \& Society 14, No. 3 (2013): 498-506.

Yates, JoAnne. "Understanding Historical Methods in Organization Studies." In M. Bucheli and R. D. Wadhwani (eds), Organizations in Time: History, Theory, Methods. Oxford: Oxford University Press, 2014, pp. 265-283.

Zald, Mayer N. "Organization studies as a scientific and humanistic enterprise: toward a reconceptualization of the foundations of the field." Organization Science 4, No. 4 (1993): 513-528.

\section{Notes}

1. Both in this volume.

2. Decker, “The Silence of the Archives”; Kipping, Wadhwani and Bucheli, "Analyzing and Interpreting Historical Sources".

3. Boldizzoni, The Poverty of Clio.

4. http://www.oxforddictionaries.com/definition/english/method

5. Here is where for instance Stinchcombe, The Logic of Social Research sees the specific role for historical methods in social research as compared to quantitative, ethnographic and experimental ones.

6. E.g. Berg and Lune, Qualitative Research Methods; Buchanan and Bryman, The SAGE Handbook of Organizational Research Methods.

7. Hansen and Wadhwani, "Can Business History”; Wadhwani and Bucheli, "The Future of the Past”. 
8. Sewell, Logics of History.

9. Rowlinson, Hassard, and Decker, "Research Strategies for Organizational History".

10. Decker, “The Silence of the Archives”; Kipping, Wadhwani, and Bucheli, "Analyzing and Interpreting Historical Sources"; Schwarzkopf, "What is an archive".

11. Fear, "Mining the Past"; Wadhwani and Bucheli, "The Future of the Past"; Yates, "Understanding Historical Methods".

12. Ricoeur, Time and Narrative.

13. Lamoreaux, Raff, and Temin, "Beyond markets and hierarchies".

14. Raff, "How to Do Things with Time”; see also Winter, “An Evolutionary Program”. 15. Callon, "Introduction: the embeddedness"; Callon, Millo and Muniesa, Market Devices. 16. Fridenson, "Business History and History”.

17. Lipartito, “Culture”; Hansen, “Organizational Culture”; Hansen, “Business History”; Mordhorst, "From Counter-factual History”.

18. Scranton and Fridenson, Reimagining Business History, 9 and 38.

19. E.g. Beckert, Monied Metropolis; Galambos, “Is this a decisive moment?”; Mihm, Nation of Counterfeiters; Ott, When Wall Street; Hyman, Debtor Nation.

20. For more detail on the scientization of business education and research and the related marginalization of historical approaches, see Engwall, Üsdiken and Kipping, "Public science systems”; Üsdiken and Kipping. “History and Organization Studies”.

21. Zald, "Organization Studies", 526-27.

22. Kieser, "Why Organization Theory Needs Historical Analyses".

23. Galambos, “The Emerging Organizational Synthesis”; idem., “Technology, Political Economy, and Professionalization”.

24. Clark and Rowlinson, "The treatment of history"; Rowlinson and Hassard, "History and the Cultural Turn"; Hansen, “Organizational Culture”. 
25. Carter, “The Age of Strategy”; McKinlay, 'Dead Selves'; McKinlay, Following Foucault.

26. Kipping and Üsdiken, "History in Organization and Management Theory".

27. Freeland, The Struggle for Control. Interestingly enough, even if the book does not rely on hypothesis testing, de Jong et al. also use it to back up their claims for a new business history.

28. Rowlinson, Hassard, and Decker, Research Strategies for Organizational History.

29. Jones, Renewing Unilever.

30. Chandler, Strategy and Structure; idem., The visible hand.

31. Gelderblom, de Jong and Jonker. "The Formative Years of the Modern Corporation”. 32. McKinlay, "'Dead Selves"'; idem., "Following Foucault"; Decker, "Solid Intentions". 33. Maclean, Harvey and Chia, "Sensemaking; Popp and Holt, Entrepreneurship and the organization of being;" Popp and Holt, "The presence of entrepreneurial opportunity.” 34. Jones et al., "Rebels with a Cause;” Khaire and Wadhwani, “Changing Landscapes;” Suddaby et al., "Historical Institutionalism;” Hargadon and Douglas, "When Innovations Meet Institutions.”

35. Bruce and Nyland. "Elton Mayo"; Hassard, "Rethinking the Hawthorne Studies”; O'Connor, "The Politics of Management Thought”.

36. Foster et al., "History as a Social Memory Asset"; Suddaby, Foster and Trank, "Rhetorical History"; Anteby and Molnár, "Collective memory".

37. See namely Burgelman, "Bridging history and reductionism”; Kipping and Lamberg. "Historical methods"; and, in general, Langley, “Strategies”.

38. Chandler, “Organizational Capabilities”.

39. E.g. Daneels, “Trying to Become a Different Type of Company”; Tripsas and Gavetti, “Capabilities, Cognition, and Inertia”.

40. Lippmann and Aldrich, History and Evolutionary Theory. 
41. Suddaby, Foster, and Mills, Historical Institutionalism.

42. Kipping and Üsdiken, History in Organization and Management Theory; Yates,

Understanding; Lipartito, Historical Sources and Data; Wadhwani and Bucheli, The Future of the Past; Fear J. Mining the Past.

43. Rowlinson and Hassard, History and the Cultural Turn. 